\title{
Effects of food allergy on the dietary habits and intake of primary schools' Cypriot children
}

Department of Life and Health Sciences, University of Nicosia, Cyprus

\section{KEY WORDS}

Food allergy; primary school children; food choices; elimination

diet; quality of life

\section{Corresponding author}

Emilia Vassilopoulou

Life and Health Sciences,

University of Nicosia

46 Makedonitissas Ave.

P.O. Box 24005, 1700 Nicosia, Cyprus

Phone: +3579902 7016; +306973353022

Fax: +35722660560

E-mail: vasilopoulou.e@unic.ac.cy;

vassilopoulouemilia@gmail.com

\section{Doi}

10.23822/EurAnnACI.1764-1489.07

\begin{abstract}
Summary
Aim. To determine whether food allergy affects overall dietary intake and food choices in Cypriot primary school children. Methods. As part of the first epidemiological study in Cyprus on food allergy in primary school children, two 24-hour recalls (one from a week and one from a weekend day) of twenty-eight food allergic children (21 girls) and thirty healthy children (20 girls) aged 6-11 years old, were analysed and compared regarding their macro-and micronutrient content, food choices and meal distribution. Results. Significant differences between the two subgroups of children were estimated regarding the total energy intake and macronutrients, where food allergic children were found to consume in lower quantities, as well as for calcium, niacin, fiber and vitamin E. Food allergic children were also found to avoid combining foods from the various food groups in their meals, and to prefer specific food products from each category, whereas they consumed higher amounts of sugar and fructose. Conclusion. Food allergy in Cypriot food allergic children impacts on both the quality and quantity of food choices, probably due to lack of nutritional education regarding proper elimination diet and alternative nutrient sources.
\end{abstract}

\section{Introduction}

Most children develop food allergies within the first 5 years of life, one of the most crucial periods of growth and development (1). Among the most common food allergens in the pediatric population are milk, wheat and egg (2), which constitute the main sources of significant nutrients, such as protein, iron and calcium (3). An elimination diet creates an emerging need for alternative sources of all basic macro- and micronutrients, as the diet of food allergic children is in several cases found low in energy, protein, calcium, vitamins $\mathrm{D}$ and $\mathrm{E}$, iron and zinc (4), due to inappropriate food exclusions and follow-up after diagnosis of food allergies, but also refusal of food allergic children to try new foods (5), resulting to rickets, kwashiorkor, anaemia and failure to thrive in long-term (6). Furthermore, without ap- propriate dietary education on the everyday management (i.e allergen labelling, alternative foods) (7), psychosocial problems arise $(8,9)$ due to high levels of anxiety associated with a potential accidental reaction (5).

The current study aims to identify the effect of food allergy on dietary habits and intake of food allergic in comparison to healthy primary school Cypriot children.

\section{Patients and Methods}

Study design

A survey with a specially composed questionnaire for self- reported food allergy (10) was performed among primary schoolchildren, aged 6-11years old, in Cyprus. Stratified random sam- 
pling was used to select 15 schools in urban and rural areas of Cyprus and 3000 questionnaires were distributed, containing also a request for completion of two 24-hour recalls (one from a week and one from a weekend day).

311 completed questionnaires were returned, among which only 59 contained the completed two 24-hour recalls.

The study was approved by the Cypriot Bioethics Committee and the Cypriot Ministry of Education, and informed consent was returned completed together with the questionnaires by the parent or the guardian.

\section{Data analysis}

The 24-hour recalls were analysed with dietplan 6.70 (11) to determine the macronutrient and micronutrient consumption of food allergic versus healthy children. To evaluate the impact of food allergy on food choices and meal distribution, these were also analysed and compared with the respective from the healthy individuals. Mann-Whitney U test and Pearson Chi-Square test were used (12) and p-values lower than 0.05 were considered as statistically significant.

\section{Results}

Among all distributed questionnaires, only $10.4 \%$ were returned completed and from these only $19 \%(\mathrm{n}=51)$ included the two 24-hour recalls. More in detail, 28 (21 girls) with a mean age of 8.43 years $(S D \pm 1.86$ ), reported a confirmed food allergy by a doctor with skin prick test, serological evaluation and/or food challenge, and they were on a food elimination diet to one of the following: 6 to cow's milk, 3 to egg, 1 to cereals, 2 to tomato, 2 to cherry, 2 to chocolate, 4 to peanuts and 1 to orange. From the healthy participants, 30 children (20 girls) returned the 24-hour recalls completed (mean age 9.2 years, $S D \pm 1.57)$.

\section{Food choices from the different Food Groups during the day}

Food allergic were found to consume lower servings of almost all food groups, such as dairy products, bread and cereals, fruit and vegetables than the healthy children. Also, the last recorded a higher variety, with combinations of products from all groups in almost all daily meals. Wholegrain cereals and fish were more often consumed, as well as fresh fruit and vegetables. Food allergic preferred commercial juices and dry fruit to fresh fruit, and had the same breakfast in the two days of recall, containing only bread or cereals and dairy products. Overall amount of meat products was similar for both groups (figures $\mathbf{1}$ and $\mathbf{2}$ ).

\section{Energy, macronutrients and micronutrients intake}

Significant differences were observed for the estimated total energy intake for both the weekday and the weekend day. Food allergic consumed a mean of $1694 \mathrm{kcal}( \pm 230)$ for the weekday and $2105 \mathrm{kcal}( \pm 180)$ for the weekend day. In regards of the macronutrients intake, for the weekday carbohydrate intake was

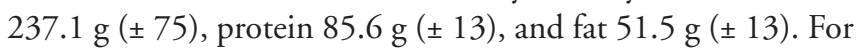
the weekend day, consumption of carbohydrate was $245.9 \mathrm{~g} \mathrm{( \pm}$ $19)$, for protein $92 \mathrm{~g}( \pm 12.8)$ and for fat $85.5 \mathrm{~g}( \pm 13.4)$.

On the other hand, healthy children consumed $2670 \mathrm{kcal}( \pm$ $285)$ on the weekday and $3030 \mathrm{kcal}( \pm 270)$ on the weekend

Figure 1 - Distribution of foods group consumed during the day (week or weekend day).

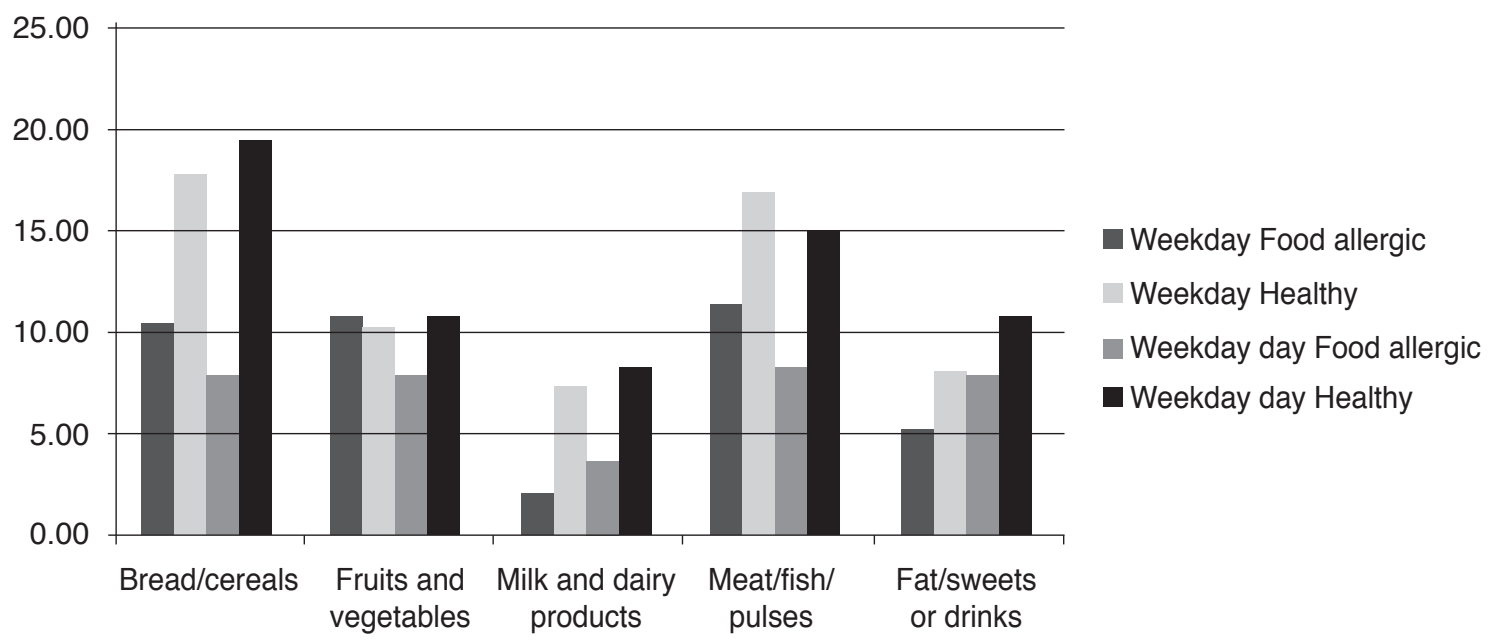


Figure 2 - Relative distribution of food groups in all daily meals (breakfast, mid-morning snack, lunch, mid-afternoon snack and dinner) in both 24-hour recalls.

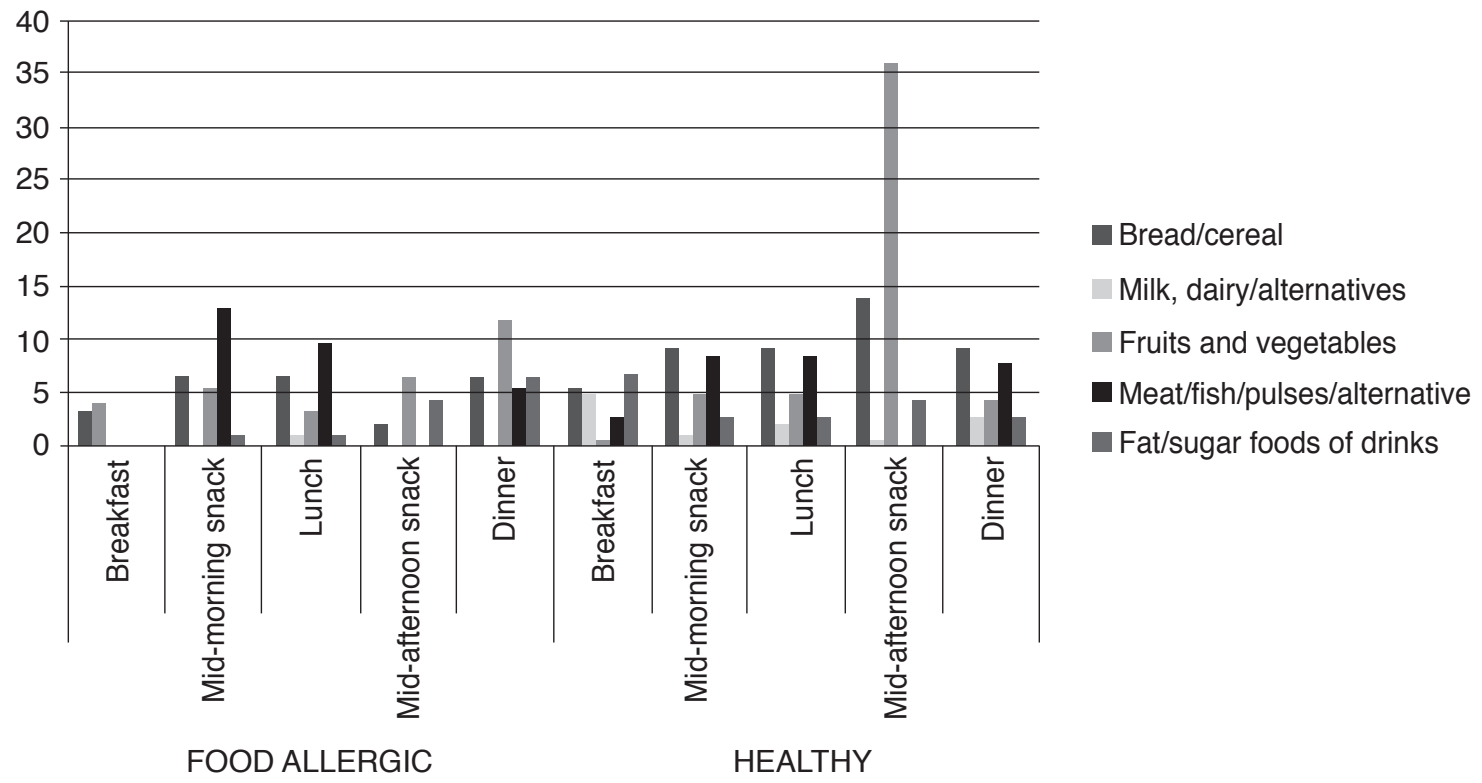

day. Regarding their macronutrient intake for the weekday these were $276.2 \mathrm{~g}( \pm 43.7)$ for carbohydrates, $127.1 \mathrm{~g}( \pm 18)$ for protein and $84.2 \mathrm{~g}( \pm 16.9)$ for fat. Mean carbohydrate consumption during the weekend was $406.7 \mathrm{~g}( \pm 80)$, for protein 132.6 $( \pm 19.5)$ and for fat $113 \mathrm{~g}( \pm 28)$.

In regards of micronutrients intake, food allergic children were found to consume significantly higher amounts of sugar and fructose $(\mathrm{p}=0.043)$, whereas lower amounts of calcium $(\mathrm{p}=$ $0.046)$, vitamin niacin $(\mathrm{p}=0.033)$, fibre $(\mathrm{p}=0.037)$ and vita$\min \mathrm{E}(\mathrm{p}=0.049)$.

\section{Discussion}

The current study, part of the first epidemiological study on food allergy in Cypriot primary school children, evaluated the effect of food allergy on dietary intake and food choices of Cypriot primary school children through two 24-hour recalls, in comparison to their healthy peers. Children who self-reported themselves as food allergic were found to have lower energy, calcium, niacin, vitamin E, fibre intake, and variety of food choices on daily meals, whereas sugar and fructose were higher than the ones of healthy children.

To start with, food allergic children had lower energy intake and overall macronutrient consumption. This could be due to the monotonous diet they reported to follow, and to the avoidance of combining foods from different food groups in their meals. This could be due to the anxiety they experience due to the food allergy, resulting into food refusal, aversion and/or food neophobia affecting, as reported elsewhere, the overall nutrient intake and leading to growth disturbances and malnutrition $(9,13,14)$. Additionally, the quality of life can be disturbed, as shown by different researchers, where food allergy was shown to cause psychological distress and anxiety to the children and their families (14), which avoided social events.

Children with food allergies are at risk of developing eating disorders (15). Although all children in our study reported that they were sharing family meals, the food allergic ones did not increase either the quantity or variety of food they consumed, nor the quality. Opposite to this, food choices were found unhealthier in the food allergic, that were consuming more sugar, in line with other studies (16).

Fruits and vegetables were consumed in lower amounts, especially during the weekend by the food allergic. Fructose intake was found higher though, probably due to the higher consumption of fruit juices and dry fruit such as dry figs. These are in line with other studies, showing that food allergy affects choices in fruit and vegetables, usually by increasing fruit consumption and lowering vegetables $(17,18)$.

Calcium intake was relatively lower, due to lower amount of milk and dairy products or inadequate alternatives consumed. Milk and dairy products are key foods for children's growth and development, as they are rich in protein, fat, vitamin A, vitamin $\mathrm{D}$, riboflavin, pantothenic acid, vitamin $\mathrm{B} 12$, calcium, 
phosphorous and niacin (19). Elimination diet to dairy without appropriate substitution can lead to insufficient intake of basic nutrients and pronounced delay of growth (20).

Significantly lower fiber in allergic children could be relevant to the low intake of whole grain products consumed. Limited consumption of starch also affects negatively vitamin $\mathrm{D}$, calcium, zinc, iron and vitamins B intake (21). Choosing processed products, such as white instead of whole-wheat bread could be due to lack of knowledge of the nutritional value of whole gains or to financial difficulties leading to choose processed products rather than whole-wheat (22). Also, lower niacin levels could be due to the relatively lower dairy and starch intake, as also reported elsewhere (23).

Vitamin E intake was significantly lower in food allergic children, probably due to the lower consumption of vegetable oils. Vitamin $\mathrm{E}$ is associated with optimal health and cell protection from oxidative damage (24), whereas it can have a protective role together with other antioxidants against allergies (25).

The current study revealed several significant differences between nutrient intake and food variety among healthy and food allergic elementary school children, despite the low rates of response. Unfortunately, we did not have sufficient data related to the anthropometric measurements (height and weight) of the participants, in order to determine growth disturbances.

The 24-hour recalls used as the main tool to evaluate food consumption, qualitatively and quantitatively, revealed several differences among the two subgroups, despite the low rates of response. Although there was a request for completing in parallel a food frequency questionnaire regarding the dietary habits of the last 6 months (26), in order to have an overall estimation of the diet, we did not achieve to have a significant number returned, to come into significant estimates.

\section{Conclusion}

Food allergic elementary school children have a less variety of foods in their diet, and their overall intake is lower, resulting on several significant differences in macronutrients and micronutrients, in comparison to their healthy peers. This could be due to the anxiety caused by a putative new allergic reaction or to limited education on sufficient alternatives.

\section{Acknowledgements}

Sincere acknowledgements to University of Nicosia for covering the cost for the 3000 reprints of the questionnaires. Special thanks to the students of the Department of Nutrition and Dietetics of University of Nicosia for their contribution on data collection.

\section{References}

1. Gupta, R.S., Springston, E.E., Warrier, M.R., Smith, B., Kumar, R., Pongracic, J., et al. The prevalence, severity, and distribution of childhood food allergy in the United States. Pediatrics. 2011;128(1):e9-17.

2. Venter, C. \& Meyer, R. Session 1: allergic disease: the challenges of managing food hypersensitivity. Proc Nutr Soc. 2010;69(1): 11-24.

3. Mehta, H., Groetch, M., \& Wang, J. Growth and nutritional concerns in children with food allergy. Curr Opin Allergy Clin Immunol. 2013;13(3):275-9.

4. Somers, L. Food allergy: Nutritional considerations for primary care providers. Pediatric Annals. 2008;37(8):559-68.

5. Le, T. M., Zijlstra, W. T., van Opstal, E. Y., Knol, M. J., L’Hoir, M. P., Knulst, A. C., et al. Food avoidance in children with adverse food reactions: Influence of anxiety and clinical parameters. Pediatr Allergy Immunol: Official Publication of the European Society of Pediatric Allergy and Immunology. 2013;24(7):650-5.

6. Alvares, M., Kao, L., , V., Clark, A. \& Andrew, J.B. Misdiagnosed Food Allergy Resulting in Severe Malnutrition in an Infant. Pediatrics. 2013;132(1):e229-e232.

7. Sakellariou A, Sinaniotis A, Damianidou L, Papadopoulos NG, Vassilopoulou E. Food allergen labelling and consumer confusion. Allergy. 2010;65(4):534-5.

8. Flokstra-de Blok, B. M., van der Meulen, G. N., DunnGalvin, A., Vlieg-Boerstra, B. J., Oude Elberink, J. N., Duiverman, E. J., et al. Development and validation of the food allergy quality of life questionnaire - adult form. Allergy. 2009;64(8):1209-17.

9. Polloni, L., Toniolo, A., Lazzarotto, F., Baldi, I., Foltran, F., Gregori, D., et al. Nutritional behavior and attitudes in food allergic children and their mothers. Clin Transl Allergy. 2013;3(1):41. doi:10.1186/2045-7022-3-4.

10. Kavaliūnas A, Surkienė G, Dubakienė R, Stukas R, Zagminas K, Saulyte J, et al. EuroPrevall survey on prevalence and pattern of self-reported adverse reactions to food and food allergies among primary schoolchildren in Vilnius, Lithuania. Medicina (Kaunas). 2012;48(5):265-71.

11. Forestfield Software. (2012). Dietplan6 nutrition analysis software (6.70th ed.). Horsham West Sussex: Forestfield Software Ltd.

12. IBM Corp. (2012). IBM SPSS statistics for windows (21.0th ed.). Armonk, NY: IBM Corp.

13. Somers, L.S. Peanut allergy: Case of an 11-year-old boy with a selective diet. J Am Diet Assoc. 2011;111(2):301-6.

14. Cummings, A.J., Knibb, R.C., King, R.M. \& Lucas, J.S. The Psychosocial impact of food allergy and food hypersensitivity in children, adolescents and their families: a review. Allergy. 2010;65:933-45.

15. Noimark, L., \& Cox, H.E. Nutritional problems related to food allergy in childhood. Pediatr Allergy and Immunol. 2008;19(2):188-95.

16. Salvy, S.J., Elmo, A., Nitecki, L.A., Kluczynski, M.A., \& Roemmich, J.N. Influence of parents and friends on children's and adolescents' food intake and food selection. Am J Clin Nutr. 2011;93(1):87-92.

17. Cooke, L. J., \& Wardle, J. Age and gender differences in children's food preferences. Br J Nutr. 2005;93(05):741-6.

18. Rosenlund, H., Kull, I., Pershagen, G., Wolk, A., Wickman, M., $\&$ Bergström, A. Fruit and vegetable consumption in relation to al- 
lergy: Disease-related modification of consumption? J Allergy Clin Immunology. 2011;127(5):1219-25.

19. Rona, R. J., Keil, T., Summers, C., Gislason, D., Zuidmeer, L., Sodergren, E., et al. The prevalence of food allergy: A meta-analysis. J Allergy Clin Immunology. 2007;120(3):638-46.

20. Mehta, H., Groetch, M. \& Wang, J. Growth and Nutritional Concerns in Children with Food Allergy. Curr Opin Allergy Clin Immunol. 2013;13(3):275-9.

21. Penagini, F., Dilillo, D., Meneghin, F., Mameli, C., Fabiano, V., \& Zuccotti, G.V. Gluten-free diet in children: An approach to a nutritionally adequate and balanced diet. Nutrients. 2013;5(11):45.

22. Nicklas, T. A., Jahns, L., Bogle, M. L., Chester, D. N., Giovanni, M., Klurfeld, D.M., et al. Barriers and facilitators for consumer adherence to the dietary guidelines for americans: The HEALTH study. J Acad Nutr Diet. 2013;113(10):1317-31.
23. Henriksen C1, Eggesbø M, Halvorsen R, Botten G. Nutrient intake among two-year-old children on cows' milk-restricted diets. Acta Paediatr. 2000;89(3):272-8.

24. Traber, M.G., \& Stevens, J.F. Vitamins C and E: Beneficial effects from a mechanistic perspective. Free Radic Biol Med. 2011;51(5):1000-13.

25. Rosenlund H, Magnusson J, Kull I, Håkansson N, Wolk A, Pershagen $\mathrm{G}$, et al. Antioxidant intake and allergic disease in children. Clin Exp Allergy. 2012;42(10):1491-500. doi: 10.1111/j.13652222.2012.04053.

26. Garcia-Larsen V, Luczynska M, Kowalski ML, Voutilainen H, Ahlström M, Haahtela T, et al. Use of a common food frequency questionnaire (FFQ) to assess dietary patterns and their relation to allergy and asthma in Europe: pilot study of the GA2LEN FFQ. GA2LEN-WP 1.2 'Epidemiological and Clinical Studies'. Eur J Clin Nutr. 2011;65(6):750-6. doi: 10.1038/ejen.2011.15. 